\title{
Penerapan Model Pembelajaran Generatif Pada Materi Usaha dan Pesawat Sederhana Kelas VIII MTs Nurussalam Sidogede OKU Timur
}

\author{
Effendi*, Dwi Pantriani \\ Program Studi Pendidikan Fisika STKIP Nurul Huda Sukaraja, Indonesia \\ *e-mail: effendi@stkipnurulhuda.ac.id
}

Received: October 13 ${ }^{\text {rd }}$, 2019. Accepted: January 27th 2020 . Published: February $29^{\text {th }}, 2019$

\begin{abstract}
Abstrak
Tujuan penelitian ini untuk mengetahui efektivitas penerapan model pembelajaran generatif terhadap hasil belajar peserta didik pada materi Usaha dan Pesawat Sederhana di kelas VIII MTs Nurussalam Sidogede. Penelitian ini merupakan jenis penelitian kuantitatif. Populasi dalam penelitian ini adalah peserta didik kelas VIII di MTS Nurussalam Sidogede yang terdiri dari 4 kelas. Pengambilan sampel dalam penelitian ini secara acak melalui pengundian. Pembelajaran pada kelas eksperimen menggunakan model pembelajaran generatif (generative learning), sedangkan kelas kontrol menggunakan model pembelajaran konvensional. Teknik pengumpulan data menggunakan tes, dan pengujian hipotesisnya menggunakan uji-t. Berdasarkan hasil belajar peserta didik diperoleh nilai $t_{\text {hitung }}=3,09$ yang lebih besar dibanding $t_{\text {tabel }}=2,01$ sehingga dapat disimpulkan bahwa terdapat perbedaan hasil belajar yang signifikan antara peserta didik dengan model pembelajaran generatif (generative learning) dan peserta didik dengan model pembelajaran konvensional.
\end{abstract}

\begin{abstract}
The purpose of this study was to determine the effect of the application of Generative learning models on student learning outcomes in the Work and Simple Machine in MTs Nurussalam Sidogede grade VIII. The type of this research is a quantitative research. The population in this research were students of class
\end{abstract}


VIII at MTS Nurussalam Sidogede consisting of 4 classes. Sampling in this study was randomly drawn. The experimental class uses the generative learning model, while the control class uses the conventional learning model. Data collection techniques using tests, and testing of hypotheses using t-test. Based on student learning outcomes obtained $t_{\text {count }}=3.09$ which is more than $t_{\text {table }}=2.01$; so it can be concluded that there are significant differences in learning outcomes between students with generative learning models and students with conventional learning models. C2020PERJ

Keywords: Generative learning; physics learning outcomes; simple machine work.

\section{PENDAHULUAN}

Pendidikan merupakan proses pertolongan yang terus menerus dari penyesuaian yang lebih tinggi bagi manusia yang telah berkembang secara fisik dan mental, yang bebas dan sadar kepada Tuhan, seperti termanifestasi dalam alam sekitar intelektual, emosional, dan kemanusiaan. Melalui pendidikan, manusia dapat merubah tingkah laku dan kepribadian yang lebih baik. Salah satu hal yang sering dilakukan yakni kegiatan pembelajaran. Proses pembelajaran terutama pembelajaran IPA diharapkan dapat berpusat pada siswa. Balanay menyatakan bahwa penerapan pembelajaran berpusat siswa pada pembelajaran IPA dapat melatih siswa untuk mengembangkan keterampilan proses sains (Balanay, 2013). Proses pembelajaran yang baik adalah pembelajaaran yang mampu mengarahkan siswa pada proses pemecahan masalah. Selcuk menyatakan bahwa dengan siswa belajar memecahkan masalah dengan model apapun pada dasarnya akan mengarah pada keberhasilan hasil belajar siswa (Selcuk \& Mahmed, 2013). Secara praktis, pendidikan IPA harus mampu memberikan pengalaman secara langsung kepada peserta didik sebagai upaya pengembangan kompetensi (Firdaus \& Sinensis, 2017).

Pembelajaran merupakan suatu sistem atau proses membelajarkan pembelajar yang direncanakan, dilaksanakan dan dievaluasi secara sistematis agar pembelajaran dapat mencapai tujuan secara efektif dan efesien (Komalasari, 2013). Mengajar pada hakikatnya tidak lebih dari sekedar menolong para peseta didik untuk memperoleh pengetahuan, keterampilan, sikap, 
serta ide dan apresiasi yang menjurus kepada perubahan tingkah laku dan pertumbuhan peserta didik, terlebih jika pendidik tidak memperhatikan perkembangan komunikasi siswa. Ikhsan berpendapat bahwa kemampuan pemahaman dan komunikasi siswa yang rendah sangat mungkin disebabkan oleh penggunaan model pembelajaran yang tidak sesuai (Ikhsan \& Rizal, 2014). Oleh karena itu, guru harus mampu memilah dan memilih serta menentukan pendekatan pembelajaran yang sesuai dengan materi pembelajaran, karakteristik siswa dalam proses pembelajaran serta tujuan pembelajaran (Sunandar \& Effendi, 2018). Dengan demikian kinerja guru sangat berperan dalam usaha peningkatan kualitas pembelajaran. Sejalan dengan hal tersebut, Waluya mengatakan jika kemampuan pemahaman dan komunikasi siswa yang rendah sangat mungkin dikarenakan penggunaan model pembelajaran yang tidak tepat (Waluya, 2008). Berdasarkan kedua pendapat tersebut, jelas bahwa pemilihan model akan mempengaruhi kualitas pemahaman dan komunikasi siswa.

Menurut Trianto salah satu tolak ukur bahwa peserta didik telah belajar dengan baik adalah jika peserta didik tersebut dapat mempelajari materi yang seharusnya dipelajari, sehingga indikator hasil belajar yang diinginkan dapat dicapai oleh peserta didik (Trianto, 2007).

Berdasarkan hasil observasi tahap awal pada tanggal 10 Oktober 2018 sampai tanggal 10 November 2018 di kelas VIII MTs Nurussalam, masalah pokok yang terjadi dalam proses pembelajaran adalah masih rendahnya daya serap peserta didik. Hal ini nampak pada hasil belajar peserta didik yang menunjukkan $61,78 \%$ belum mampu mencapai Ketuntasan Belajar Minimal (KBM) yang ditetapkan. Berdasarkan observasi yang dilakukan, terlihat bahwa pada saat proses pembelajaran pendidik masih menerapkan model pembelajaran konvensional. Pendidik lebih banyak mendominasi pembelajaran. Hal ini menyebabkan peserta didik kurang aktif dalam kegiatan pembelajaran.

Salah satu pendukung untuk tercapainya tujuan pembelajaran adalah model pembelajaran yang digunakan oleh pendidik. Effendi menyatakan bahwa profesionalisme guru (pendidik) sangat menentukan keberhasilan siswa dalam belajar, terutama kemampuan pencapaian hasil belajar (Effendi, 2015). Kemampuan peserta didik dalam menerima pelajaran dapat dipengaruhi dari pemilihan model pembelajaran yang tepat sehingga tujuan pembelajaran yang diingikan dapat tercapai. Berdasarkan masalah yang terjadi pada pembelajaran tersebut, perlu diterapkan model 
pembelajaran yang dapat membuat peserta didik lebih aktif, dengan tujuan dapat memperbaiki hasil belajar Fisika. Model pembelajaran yang diterapkan dalam penelitian ini adalah model pembelajaran generatif. Model pembelajaran generatif (generative learning) adalah model pembelajaran yang berorientasi pada konstruktivisme, yaitu pengetahuan dibentuk sendiri oleh peserta didik melalui pengalaman dan interaksi dengan lingkungannya. Model pembelajaran generatif (generative learning) menekankan pada pengintegrasian pengetahuan peserta didik secara aktif antara pengetahuan awal atau pengalaman yang telah dimiliki peserta didik sebelumnya dengan materi yang dipelajari melalui peran aktifnya dalam pembelajaran. Model pembelajaran generatif diharapkan mampu membuat peserta didik agar lebih terlatih untuk belajar penemuan, membuat hipotesis, pengumpulan data, analisis data dan penyimpulan dari penyelesaian masalah dengan bimbingan seorang pendidik. Alba menyatakan bahwa pembelajaran dengan model generatif efektif terhadap kemampuan pemecahan masalah siswa (Alba et al., 2013).

Model pembelajaran generatif memiliki empat tahap, yaitu eksplorasi, pemfokusan tentang tantangan dan aplikasi melalui fase fase yang terdapat pada model pembelajaran generatif, siswa dapat memiliki kemampuan dan keterampilan untuk membangun pengetahuannya secara mandiri (Wena, 2009). Ketika peserta didik aktif dalam proses belajar maka diharapkan tujuan pembelajaran dapat tercapai. Apabila tujuan pembelajaran tercapai, maka dapat dikatakan bahwa pendidik telah berhasil melaksanakan proses pembelajaran. Keberhasilan kegiatan pembelajaran dapat diketahui dari hasil belajar peserta didik yang optimal.

\section{METODE}

Penelitian yang digunakan dalam penelitian ini adalah jenis penelitian kuantitatif. Pengambilan data sampel menggunakan teknik random sampling, karena di MTs Nurussalam Sidogede tidak ada kelas unggulan, sehingga setiap kelas dianggap homogen. Populasi dalam penelitian ini berjumlah 97 siswa, dengan sampel sebanyak 46 siswa. Pemilihan kelas eksperimen dan kelas kontrol dilakukan dengan cara pengundian.

Desain yang digunakan dalam penelitian yaitu memberikan treatment pada kelas eksperimen menggunakan model pembelajaran generatif, sedangkan kelas kontrol menggunakan model pembelajaran konvensional. Lebih jelasnya dapat dilihat pada Tabel 1. 
Phy. Educ. Res. J. Vol. 2 No. 1 (2020), 59-68

Tabel 1. Rancangan Penelitian

\begin{tabular}{ccc}
\hline Kelas & Perlakuan & Postest \\
\hline Eksperimen & $\mathrm{X}_{1}$ & $\mathrm{O}_{1}$ \\
\hline Kontrol & $\mathrm{X}_{2}$ & $\mathrm{O}_{2}$ \\
\hline
\end{tabular}

Kegiatan pengumpulan data dilakukan dengan teknik tes. Sebelum soal tes digunakan untuk pengumpulan data, terlebih dahulu dilakukan proses uji validitas, reliabilitas, daya pembeda dan tingkat kesukaran soal (Anwar et al., 2019).

Setelah data terkumpul kemudian dilakukan analisis data hasil penelitian. Pengujian hipotesis dilakukan menggunakan uji $t$, setelah dipastikan data memenuhi kriteria normalitas data penelitian.

\section{HASIL DAN PEMBAHASAN}

Berdasarkan analisis data yang dilakukan, diperoleh hasil bahwa nilai kelas eksperimen lebih tinggi dibanding kelas kontrol. Hal ini dapat dilihat dalam Tabel 2 . Apabila ditinjau dari kategorisasi nilai siswa, diperoleh hasil sesuai Tabel 3.

Tabel 2. Rangkuman Skor Tes Hasil Belajar Fisika Peserta Didik

\begin{tabular}{cccccc}
\hline No & Kelas & Skor Tertinggi & $\begin{array}{c}\text { Skor } \\
\text { Terendah }\end{array}$ & Rata-rata & $\begin{array}{c}\text { Standar } \\
\text { Deviasi }\end{array}$ \\
\hline 1 & Eksperimen & 95 & 55 & 76 & 9,16 \\
\hline 2 & Kontrol & 90 & 50 & 67,95 & 9,43 \\
\hline
\end{tabular}

Tabel 3. Persentase Hasil Belajar Peserta Didik Ditinjau dari Persentase Nilai Kategori Tinggi, Sedang, dan Rendah

\begin{tabular}{cccccc}
\hline \multirow{2}{*}{ No } & Kategori & \multicolumn{2}{c}{ Kelas Eksperimen } & \multicolumn{2}{c}{ Kelas Kontrol } \\
\cline { 3 - 6 } & Jumlah Siswa & $\begin{array}{c}\text { Persentase } \\
(\%)\end{array}$ & Jumlah Siswa & $\begin{array}{c}\text { Persentase } \\
(\%)\end{array}$ \\
\hline 1 & Tinggi & 6 & 26,08 & 2 & 8,7 \\
\hline 2 & Sedang & 15 & 65,22 & 15 & 65,22 \\
\hline 3 & Rendah & 2 & 8,7 & 6 & 26,08 \\
\hline
\end{tabular}

Uji normalitas menunjukkan bahwa secara umum data terdistribusi normal. Berdasarkan hasil uji $\mathrm{t}$ diperoleh hasil bahwa nilai $t_{\text {hitung }}=3,09$ lebih besar dibanding nilai $t_{\text {tabel }}=2,01$ sehingga Ho ditolak dan Ha diterima. Hal ini berarti bahwa terdapat perbedaan hasil belajar yang signifikan antara peserta didik dengan model pembelajaran generatif (generative learning) dan peserta didik dengan model pembelajaran konvensional. Perbedaan ini terjadi karena pada model pembelajaran generatif (generative leararning), interaksi dua arah berlangsung secara konsisten antara pendidik dan peserta didik. 
Interaksi tersebut antara lain pendidik membantu peserta didik untuk membuat rumusan masalah pada materi pembelajaran. Setelah rumusan masalah terbentuk, pendidik memberikan kesempatan kepada peserta didik untuk melakukan pemecahan masalah dengan cara menggali informasi sebanyak-banyaknya melalui membaca dan bertanya kepada teman. Peserta didik kemudian diberi tugas untuk menganalisis dan mencari solusi dari permasalahan yang ada. Peserta didik juga harus menetapkan jawaban atau dugaan sementara dari masalah tersebut. Dugaan sementara diperoleh dari data yang ada. Selain itu, peserta didik juga melakukan pengujian hipotesis dan menyusun kesimpulan dengan bantuan pendidik.

Interaksi antara peserta didik dan pendidik pada model pembelajaran konvensional cenderung satu arah. Pembelajaran dimulai dengan pendidik mengukapkan masalah yang akan dipelajari beserta pengarahan mengenai cara mencapai solusi pemecahannya. Pembelajaran konvensional menjadikan peserta didik lebih dominan sebagai pendengar dari materi yang disampaikan oleh pendidik. Peserta didik selanjutnya memecahkan masalah sendiri tanpa disertai dengan proses diskusi kelompok. Masing-masing peserta didik pada akhirnya harus melaporkan hasil pemecahan yang kemudian ditanggapi oleh pendidik.

Berdasarkan perbedaan proses pembelajaran pada model generatif dan konvensional, tampak bahwa pada pembelajaran generatif siswa lebih aktif, kreatif dan pembelajaran tersebut dapat memicu siswa untuk berpikir kritis. Hal ini disebabkan pembelajaran generatif menekankan pengintegrasian aktif materi baru dengan skema yang ada di benak siswa (Hamdani et al., 2012). Model pembelajaran generatif juga lebih efektif dalam meningkatkan kemampuan berpikir kreatif pada siswa beserta aspek-aspeknya (Wijaya et al., 2014). Penggunaan model pembelajaran generatif berbasis hands-on activity mampu mengoptimalkan kemampuan berpikir kritis siswa dalam kegiatan pembelajaran (Uki et al., 2017). Hasil penelitian Hutapea menunjukkan bahwa model pembelajaran generatif mampu meningkatkan kemampuan penalaran, komunikasi matematis dan kemandirian belajar siswa (Hutapea, 2013).

Model pembelajaran generatif mampu meningkatkan pemahaman konsep dan mengurangi terjadinya miskonsepsi. Firmansyah (2016) menjelaskan bahwa miskonsepsi siswa dapat dikurangi melalui penerapan model pembelejaran generatif. Pembelajaran generatif 
memberikan dampak yang lebih baik dalam meningkatkan penguasaan konsep fisika untuk siswa Sekolah Menengah Kejuruan (Maknun, 2015). Bahkan hasil penelitian Farouk \& Elfateh (2016) menunjukkan bahwa model pembelajaran generatif yang dilaksanakan selama 8 minggu dapat meningkatkan kemampuan berpikir strategis tingkat kinerja dasar yang ofensif.

Berdasarkan uraian yang telah dipaparkan, proses pembelajaran dengan model generatif mampu memperkenalkan konsep dan memungkinkan peserta didik untuk mengadopsi informasi baru terhadap apa yang sudah diketahui sebelumnya. Pemahaman konsep akan meningkatkan minimal terjadinya miskonsepsi pada pembelajaran fisika. Dengan demikian, secara keseluruhan hasil belajar fisika peserta didik akan meningkat melalui model pembelajaran generatif.

\section{KESIMPULAN}

Berdasarkan hasil analisis data dapat disimpulkan bahwa terdapat perbedaan yang signifikan antara hasil belajar peserta didik yang pembelajarannya menggunakan model pembelajaran generatif dengan model pembelajaran konvensional pada materi usaha dan pesawat sederhana di kelas VIII MTs Nurussalam Sidogede Tahun Pembelajaran 2019/2020.
Siswa yang diajar dengan model pembelajaran generatif memperoleh hasil belajar yang lebih baik secara signifikan dibanding kelas kontrol yang menggunakan metode konvensional.

\section{UCAPAN TERIMA KASIH}

Kepada seluruh pihak yang telah berkontribusi dan memberikan bantuan atas penyelesaian laporan penelitian ini, hingga dari awal hingga akhir.

\section{DAFTAR PUSTAKA}

Alba, F. M., Chotim, M., \& Junaedi, I. 2013. Keefektifan Model Pembelajaran Generatif dan MMP Terhadap Kemampuan Pemecahan Masalah. Kreano, Jurnal Matematika KreatifInovatif, 4(2), 131-137.

Anwar, C., Saregar, A., Yuberti, Y., Zellia, N., Widayanti, W., Diani, R., \& Wekke, I. S. 2019. Effect size test of learning model ARIAS and PBL: concept mastery of temperature and heat on senior high school students. Eurasia Journal of Mathematics, Science and Technology Education, 15(3), 1-9.

Balanay, C. A. S. 2013. Assessment on Students' Science Process Skills: A Student- Centred Approach. International Journal of Biology Education, 3(1). 
Phy. Educ. Res. J. Vol. 2 No. 1 (2020), 59-68

Effendi, E. 2015. Hubungan persepsi siswa terhadap penerapan model pembelajaran kooperatif tipe tutor sebaya dengan prestasi belajar fisika. Jurnal Pendidikan Fisika, 3(2).

Farouk, A., \& Elfateh, A. 2016. Effectivenes Use Generative Learning Model Onstrategic Thinking Skills and Learning Level of Basics Offensive Fencing. Directory of Open Acces Journals, 16(1), 33-38.

Firdaus, T., \& Sinensis, A. R. 2017. Keterampilan Dasar Kinerja Ilmiah Pada Mahasiswa Calon Guru Fisika. Jurnal Pendidikan Fisika, 5(2), 102-110.

Firmansyah, J. 2016. Penerapan model pembelajaran generatif untuk mengurangi miskonsepsi pada materi gerak melingkar. Jurnal Serambi Akademica, 4(1).

Hamdani, D., Kurniati, E., \& Sakti, I. 2012. Pengaruh model pembelajaran generatif dengan menggunakan alat peraga terhadap pemahaman konsep cahaya kelas VIII di SMP Negeri 7 Kota Bengkulu. Exacta, 10(1), 79-88.

Hutapea, N. M. 2013. Peningkatan kemampuan penalaran, komunikasi matematis dan kemandirian belajar siswa SMA melalui pembelajaran generatif. Universitas Pendidikan Indonesia.
Ikhsan, M., \& Rizal, S. 2014. Meningkatkan kemampuan pemahaman dan komunikasi matematis siswa sekolah menengah atas melalui model pembelajaran generatif. Jurnal Didaktik Matematika, 1(2).

Komalasari. 2013. Pembelajaran Konstektual Konsep dan Aplikasi. PT Refika Aditama.

Maknun, J. 2015. The Implementation of Generative Learning Model on Physics Lesson to Increase Mastery Concepts and Generic Science Skills of Vocational Students. American Journal of Educational Research, 3(6), 742-748.

Selcuk, C., \& Mahmed. 2013. A Comparison Of Achievement In Problem-Based, Strategic And Traditional Learning Classes In Physics. International Journal on New Trends in Education and Their Implications, 4(1).

Sunandar, D., \& Effendi, E. 2018. Penerapan Metode Brainstorming pada Pembelajaran Fisika Materi Wujud Zat. Jurnal Inovasi Pendidikan Fisika Dan Riset Ilmiah, 2(1), 38-42.

Trianto. 2007. Model-model Pembelajaran inovatif Berorientasi konstruktivisme. Prestasi Pustaka Publisher.

Uki, R. S., Saehana, S., \& Pasaribu, M. 2017. Pengaruh Model Pembelajaran Generatif 
Phy. Educ. Res. J. Vol. 2 No. 1 (2020), 59-68

Berbasis Hands-on activity pada Materi Fluida Dinamis terhadap Kemampuan Berpikir Kritis Siswa. Physics Communication, 1(2), 6-11.

Waluya, B. 2008. Penggunaan Model Pembelajaran Generatif untuk Meningkatkan Pemahaman Siswa pada Konsep Geografi. Jurnal Pendidikan Geografi FPIPS UPI, 2(1), 1-9.
Wena. 2009. Strategi Pembelajaran Inovatif Kontemporer (Suatu Tinjauan Konseptual Oprasional. PT. Bumi Aksara.

Wijaya, I. K. W. B., Suastra, I. W., \& Muderawan, I. W. 2014. Pengaruh Model Pembelajaran Generatif terhadap Keterampilan Berpikir Kreatif dan Keterampilan Proses Sains. 
Phy. Educ. Res. J. Vol. 2 No. 1 (2020), 59-68 